\title{
Reduced costs of mixed-species pairings in flycatchers: by-product or female strategy?
}

\author{
Thor Veen • Johan Träff • Franz J. Weissing • \\ Ben C. Sheldon
}

Received: 9 April 2008 /Revised: 1 September 2008 / Accepted: 16 September 2008 / Published online: 7 October 2008

(C) The Author(s) 2008. This article is published with open access at Springerlink.com

\begin{abstract}
Heterospecific matings are generally assumed to be unconditionally disadvantageous due to reduced viability or fertility of hybrid offspring. For female collared flycatchers (Ficedula albicollis) mated to male pied flycatchers (Ficedula hypoleuca), the cost of heterospecific
\end{abstract}

Communicated by S. Pruett-Jones

Electronic supplementary material The online version of this article (doi:10.1007/s00265-008-0665-6) contains supplementary material, which is available to authorized users.

T. Veen · F. J. Weissing

Theoretical Biology Group,

Centre for Ecological and Evolutionary Studies,

University of Groningen,

Kerklaan 30,

9751 NN Haren, The Netherlands

T. Veen $\cdot$ B. C. Sheldon

Edward Grey Institute, Department of Zoology,

University of Oxford,

South Parks Road,

Oxford OX1 3PS, UK

T. Veen

Department of Animal Ecology, Evolutionary Biology Centre,

Uppsala University,

Norbyvägen $18 \mathrm{D}$,

75236 Uppsala, Sweden

J. Träff

Visborgsgatan 28 A iii,

62158 Visby, Sweden

Present address:

T. Veen $(\triangle)$

Centre for Ecology \& Conservation, School of Biosciences,

University of Exeter,

Cornwall Campus,

Penryn TR10 9EZ, UK

e-mail: T.Veen@exeter.ac.uk pair formation is reduced due to high levels of conspecific extra-pair paternity and a male-biased offspring sex ratio. In order to investigate whether these cost-reducing mechanisms are the result of female mating strategies, rather than being a by-product of species incompatibilities, we manipulated the plumage of male collared flycatchers before pair formation to make them resemble male pied flycatchers. Since species incompatibilities are absent in this design, any systematic effect of manipulation on sex ratio or paternity would indicate a role of female mating strategy. Paternity was determined by means of a likelihood approach that controls the errors made in assigning a chick to be 'within-pair' or 'extra-pair'. Neither the sex ratio nor the male share of paternity was affected by the manipulation in a systematic manner. We therefore conclude that our experimental data provide no support for the suggestion that female behavioural strategies are markedly adjusted in response to formation of mixed-species pairs.

Keywords Ficedula flycatchers · Hybridisation . Extra-pair paternity $\cdot$ Mate choice $\cdot$ Species incompatibility . Paternity analysis

\section{Introduction}

Mate choice can be an important factor determining an individual's reproductive success, and incorrect mate choice can have large negative fitness consequences, especially when an individual chooses a partner of another species. Such mixed-species pairings often entail substantial fitness costs, since hybrid offspring typically have greatly reduced viability and/or fertility (e.g. Barton and Hewitt 1985; Coyne and Orr 2004). One would therefore expect strong selection against such maladaptive mate choice. Birds are 
no exception when it comes to the fertility costs of hybridisation (Price and Bouvier 2002); considering this, it is perhaps surprising that mixed-species pairings are quite regularly observed in natural bird populations (Grant and Grant 1992; McCarthy 2006).

One explanation for the occurrence of mixed-species pairings is that it results from a mistake in mate choice (e.g. Grant and Grant 1997; Irwin and Price 1999). This explanation is unlikely to hold in all cases, as species recognition has been found to be well evolved in some species engaging in mixed-species pairing (e.g. Price 2007). For these species, it is important to get good estimates of all costs and benefits of the different choice options (including mating with a conspecific or heterospecific partner) in order to understand the mating patterns observed. Several studies that have set out to do this found remarkable and counterintuitive results. In spadefoot toads, Spea bombifrons females changed their mate choice in favour of heterospecific Spea multiplicata males when living in quickly drying ponds. Hybrid tadpoles matured faster and thus had a higher survival chance compared to pure $S$. bombifrons tadpoles, and this benefit outweighed, under certain circumstances, the costs of reduced fertility of hybrid offspring (Pfennig 2007). A second example, and the focus of this study, concerns two hybridising flycatcher species. The main cost of hybridisation results from the production of infertile hybrid daughters, but in broods consisting of a female collared flycatcher (Ficedula albicollis) and a male pied flycatcher (Ficedula hypoleuca), this was strongly reduced by: (1) a high proportion of pure collared flycatcher offspring resulting from extra-pair copulations of the female with a conspecific male and (2) a sex ratio skew towards males (Veen et al. 2001). In addition, late in the season collared flycatcher females paired to a male pied flycatcher were found to fledge more young compared to pure collared flycatcher broods. Combining estimates of the costs and benefits of mixed-species pairing suggests that for a female collared flycatcher, choosing a heterospecific male at the end of the breeding season results in a fitness advantage compared to a conspecific male (Veen et al. 2001). The question we try to tackle in this study is whether the cost-reducing mechanisms described above result from an evolved female mating strategy or from mechanistic side effects, for example as a consequence of species incompatibilities. The hypotheses are treated in more detail below.

First hypothesis: an adaptive mating strategy of female collared flycatchers

When mated to a male pied flycatcher, a collared flycatcher female might adjust the sex ratio of the brood towards the more fertile (male) sex (which is not implausible, see e.g. Komdeur et al. 1997; Badyaev et al. 2006). Subsequently, collared flycatcher females paired with a pied flycatcher male might actively seek extra-pair copulations with a conspecific. This does not necessarily need to be a newly evolved adaptation when mated to a heterospecific partner but might instead be an 'extension' of intraspecific mating strategies based on trait values outside the range of conspecific partners. Male collared flycatchers with a small forehead patch lose paternity compared to large patched males in some populations (Sheldon and Ellegren 1999; Michl et al. 2002), and this might have a particularly large consequences for the very small patched pied flycatcher.

Second hypothesis: mechanistic side effect resulting from species incompatibilities

The sex ratio bias in favour of sons might represent sexbiased abortion and mortality in line with Haldane's rule (Haldane 1922): female offspring (i.e. the heterogametic sex) may suffer more from early embryonic death than male offspring. The high frequency of conspecific extra-pair paternity could be caused by an inherent advantage of conspecific sperm in sperm competition (i.e. conspecific sperm precedence: Price 1997; Fricke and Arnqvist 2004; Harper and Hart 2005).

It was the central aim of the present study to discriminate between these alternative explanations. To this end, we manipulated the white plumage parts of free-ranging male collared flycatchers before pair formation to resemble those of a male pied flycatcher. Subsequently, the pairing success, the male's share of paternity in the brood, and the sex ratio of the offspring were studied.

\section{Materials and methods}

Study species and study population

Flycatchers in the genus Ficedula are migrant sexually dimorphic insectivorous passerine birds. Both pied and collared flycatchers are cavity-nesting species, readily accepting nest boxes, and in both species, the male provides an approximately equal amount of parental care as the female. We used populations breeding in nest boxes on the island of Gotland (Sweden) that have been monitored for over 25 years by JT or by biologists based at the University of Uppsala. On Gotland, pied and collared flycatchers breed in sympatry, with the latter species being numerically dominant ( $>95 \%$ of all breeding birds); the two species hybridise in low numbers $(2-3 \%$ of the breeding pairs Veen et al. 2001). Previous studies of the mating system of the collared flycatcher have shown that extra-pair paternity occurs in around one third of all broods and that, on average, about $15 \%$ of all young are extra-pair sired 
(Sheldon and Ellegren 1999; Veen et al. 2001). Both the sex ratio and the level of extra-pair paternity are correlated with the size of the sexually selected characters (the size of the white patch on the forehead and the amount of white on the base of the primaries (Ellegren et al. 1996; Sheldon and Ellegren 1999; Michl et al. 2002)). The two species differ in several morphological characteristics, these differences being most pronounced in males. Males of the two species differ in the amount of white on the forehead, the base of the primaries and in the neck, with pied flycatchers always having less white (Svensson 1992).

\section{Experimental procedures and field data collection}

Male collared flycatchers were caught upon arrival at the breeding grounds from the beginning of May onwards in three consecutive years (2002-2004) using traps inside the nest boxes, which were triggered when males entered nest boxes to inspect them (something they do frequently when newly arrived and establishing a breeding territory). In each year, a new area was used for the experiment to avoid using the same individuals multiple times. In 2002, we aimed to catch all newly arrived males each day. These males are often very conspicuous and actively singing (personal observation); we believe that most males were caught within a day or two after arrival. In 2003 and 2004, we changed catching strategy since we had the possibility to trap very efficiently in many boxes at the same time. Every second day, we placed traps in half of all the nest boxes in our experimental area for an extensive period of time (up to $5 \mathrm{~h}$ per day with frequent checks), creating a situation in which newly arrived males were very likely to be caught within 2 days after arrival. The nest-box areas used had the following characteristics: 2002 at Sproge, 224 boxes with 50 breeding pairs; 2003 at Grötlingbo, 172 boxes with 74 breeding pairs; and 2004 at Grötlingbo, 158 boxes with 70 breeding pairs.

We assigned male collared flycatchers randomly to treatment groups within the experiment. In the 'experimental' group (from now on referred to as 'E'), the three main differences in male plumage between the two species were manipulated to match the plumage of a male pied flycatcher. In practice, this meant that the white patch on the forehead, the base of the primaries and the neck were painted with a black marker pen (Copic 100 Black) to match the mean values of a male pied flycatcher for the above-mentioned traits (forehead: height $3.6 \mathrm{~mm}$, width $7.1 \mathrm{~mm}$, white on the primaries (p), measured from the tip of the primary covert: p2-5 no white, p6 $4 \mathrm{~mm}$, p7 $5 \mathrm{~mm}$ (primaries numbered ascendently from outside of the wing inwards)). The white collar was painted by eye to resemble the collar of a pied flycatcher male. Males in the 'control' group (from now on referred to as control $1{ }^{~ '} \mathrm{C} 1$ ') received the same treatment as the E males but were painted with a marker pen without ink (Copic colourless blender) so as not to change the colour or extent of the white plumage areas (thus, males in this group resembled a normal collared flycatcher).

Previous studies have shown that differences in reflectance of ultraviolet (UV) wavelengths can be of importance for mate choice in birds (e.g. Bennett et al. 1996). In order to exclude the possibility that the manipulation changed the reflectance of wavelengths shorter than visible for humans (human range, 400-700 nm) in a way other than intended (e.g. the blackened areas), we measured the effect of the marker pens on the reflectance in the UV part of the colour spectrum (320-400 nm). This was done by measuring the reflectance of unmanipulated white and black parts of ten male median tertial feathers using a USB-2000 spectrophotometer with illumination by a DH-2000 deuterium-halogen light source (both Avantes, Eerbeek, The Netherlands). The white parts of five feathers were then treated with the colourless blender marker pen and the other five with black marker pen. The reflectance of each feather was measured again after manipulation. The reflectance curves of the manipulated white parts were almost identical to the unmanipulated white ones, and the curves of the white parts treated with black marker pen were very similar to the curves of the black areas of the feathers (data not shown). We therefore assume that our treatment did not have a major effect on the reflectance of the manipulated areas in the UV region other then intended.

In 2003 and 2004, a third group was added to the experiment. Males in this group (from now on referred to as control 0 ' $\mathrm{C} 0$ ') were only measured and a blood sample taken before being released. The purpose of adding this group was to function as control for painting per se and aims to control for unforeseen effects of painting (for example, due to olfactory cues, Moore and Moore 1999). For this reason, the $\mathrm{C} 0$ and $\mathrm{C} 1$ group will be compared to each other, after the comparison between $\mathrm{E}$ and $\mathrm{C} 1$.

From the start of the breeding season, all nest boxes were checked daily to record onset of nest building, start of egg laying and clutch size. Because we could not record the start of pair formation directly, we used the onset of nest building as the moment of pair formation. Once building of the nest started (i.e. the bottom of the nest box was covered with nesting material), the nest was, in the vast majority of cases, finished and followed by a breeding attempt (JT, personal observation). Adults were caught and measured, and ring numbers were recorded during incubation (females only) and nestling feeding (both sexes). Only at this stage could we decide whether or not to include a brood in the experiment. We had to discard all males that had been caught and manipulated after pair formation, since for these males, the manipulation was unrelated to female mate 
choice. Nestlings were ringed and measured at day 12 , where hatching is day 0 (for more details on methods, see Part and Gustafsson 1989). A blood sample (3-10 $\mu$ l) was collected by brachial venipuncture from all adults and nestlings and stored in $96 \%$ ethanol.

\section{Sex determination and paternity analysis}

The sex of the offspring in each brood was determined using primers $\mathrm{P} 2$ and $\mathrm{P} 8$ followed by standard polymerase chain reaction (PCR) procedures (Griffiths et al. 1998). The products were made visible by silver-staining on a $6 \%$ polyacrylamide gel and scored manually. Paternity in all broods was determined on the basis of allele-sharing at eight polymorphic microsatellite markers: FhU2, FhU3, FhU4, FhU5, Pdou5, Pca3, Phtr1 and Phtr2. Different sets of markers were used for different years (samples from 2002 with Fhu2, Fhu3, Fhu4, Fhu5 and Pdou5 and samples from 2003 and 2004 with all markers except Fhu5). DNA from all blood samples was extracted using Chelex extraction followed by standard PCR procedures (Ellegren 1992; Primmer et al. 1996; Saetre et al. 2001). In all years the PCR products were arranged in family groups. In 2002, these products were run out on a $6 \%$ polyacrylamide gel with size standard, made visible using silver-staining, and were scored manually after drying. The 2003 and 2004 PCR products were run on an ABI Prism 377 Sequencer with size standards and scored using GeneScan and Genotyper software packages. Egg dumping is thought to be rare in collared flycatchers (Gelter et al. 1992), and our data support this (only eight nestlings had a single mismatch with their mother, making it likely that these mismatches either reflect typing errors or mutations). We therefore assume the female caught at the nest to be the genetic mother of the offspring. In Electronic supplementary material S1, we describe in detail how paternity was determined using a likelihood approach performed by the program Cervus 3.0 (Kalinowski et al. 2007). For a given offspring and the given social mate of the known mother, Cervus calculates a LOD (logarithm of odds) score (corresponding to the logarithm of a likelihood ratio) that corresponds to the relative likelihood of obtaining the offspring genotype under the assumption that the social mate is the genetic father. These LOD scores are based on the allele frequencies at the marker loci of all adult individuals found in the study population and, therefore, take account of differences in discriminatory power between the markers. The offspring was considered a 'within-pair young' (WPY) if the LOD score was above a certain threshold value $T$, and it was considered an 'extrapair young' (EPY) if the LOD-score was lower than this threshold. As described in Electronic supplementary material S1, the threshold was determined in such a way that the probability of both types of error inherent in a paternity analysis could be controlled: (1) the misclassification of a WPY as an EPY (type I error) and (2) the misclassification of an EPY as a WPY (type II error). It turned out that in all three study years, each type of error was smaller than $2.4 \%$ (see Electronic supplementary material S1 for details).

Statistical analysis

\section{Pairing success}

If females indeed prefer conspecific over heterospecific partners as predicted, we would expect the 'pied-like' (E) males to have a lower pairing success. Pairing success refers, in this study, to the number of males of a given category caught on a given day, which were found breeding later on in the season with respect to the total number of males caught on that given day (in Fig. 1, the pairing success is presented as the proportion of successful males in relation to all males caught). The effect of experimental treatment on pairing success (the dependent variable) was analysed using a logistic regression (binomial error distributions and logit link function). Independent variables included in the full model, besides experimental treatment, were the relative date caught (relative to the first capture date for each year) as a covariate and year as a factor. An interaction term between treatment and relative date caught was included for the comparison between $\mathrm{E}$ and $\mathrm{C} 1$ to test for a seasonal change of mate preference (Qvarnstrom et al. 2000; Veen et al. 2001).

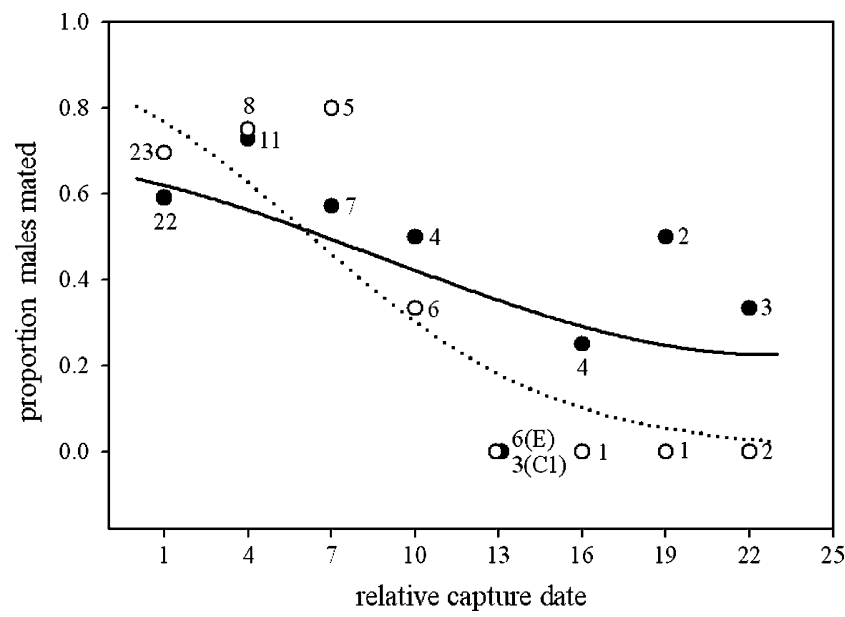

Fig. 1 The proportion of males of the $\mathrm{C} 1$ (open circles) and E (black circles) treatment groups that successfully paired relative to their day of capture (note that in the analysis the raw data was used). Day of capture is relative to the first catching day of the season. Data have been pooled in categories of 3 days, and sample sizes for each category are presented next to the plotted data. The fitted curves are predicted proportion of males mated from a logistic regression on the original (non-pooled) data (dotted line is $\mathrm{C} 1$, solid line is $\mathrm{E}$ ) 


\section{Speed of pair formation}

A second way to test for an effect of experimental treatment is to look at pairing speed, which is defined as the time in days between experimental treatment of the male and pair formation (onset of nest building). If female preferences change through the season, as suggested above, one would expect a difference in pairing speed between the two groups through the season. A general linear model (GLM; full factorial) procedure was used, with pairing speed as dependent variable, relative capture date as explanatory variable and treatment as factor.

\section{Male share of paternity and sex ratio}

First, we analysed whether the occurrence (presence/ absence) of extra-pair paternity in broods differed between the different treatment groups ( $\mathrm{C} 1$ and E) using a Fisher's exact test. Second, the effect of the experimental treatment on the dependent variables male share of paternity (number of nestling sired in a brood as numerator) and sex ratio (number of male nestlings in a brood as numerator) was analysed using a logistic regression (binomial error distributions and logit link function). Independent variables included in the full model, beside treatment and year, were laying date and the size of the male's forehead patch (width $\times$ height in $\mathrm{mm}$ ) because previous studies have shown an influence of both on male share of paternity (Sheldon and Ellegren 1999) and sex ratio (Ellegren et al. 1996; Sheldon and Ellegren 1999). For all the logistic regressions, non-significant variables were excluded from the full model in a backwards elimination process to get the final model. Values for each variable given in the results were calculated by adding the variables individually to the final significant model. Where informative, the coefficient and standard error (in parentheses) for covariates is provided to assess the direction and magnitude of the effect. In all cases, overdispersion was, if necessary, accounted for by scaling the deviances. All analyses were conducted using Statistica 7.

\section{Results}

Data selection

Over the three seasons, a total of 177 males were caught early in the season and assigned to one of the treatment groups. Of these males, we subsequently retrapped 105 males while feeding nestlings. Only those males experimentally manipulated before pair formation could be used in these analyses. In other words, males that had already paired up (measured as the start of the nest building in the nest box they were found feeding nestlings) but which were caught and manipulated after this date, were excluded; this was the case for 33 broods. Four broods were excluded from the analyses as data on the start of nest building (and hence the date of pairing) was lacking. Moreover, one E male in 2004 paired with a female pied flycatcher and was also excluded. In six cases, males were polygynous (one $\mathrm{C} 0$ male, two $\mathrm{C} 1$ males and three $\mathrm{E}$ males); the secondary broods of all bigamists were excluded to avoid pseudoreplication. The paternity analysis for three broods failed. Table 1 presents an overview of sample sizes for all three treatment categories for all 3 years, together with mean laying date and pairing speed.

Table 1 For each year and each experimental group, the numbers of males caught early in the season and subsequently found breeding are presented

\begin{tabular}{|c|c|c|c|c|c|c|c|c|c|}
\hline Year & Treatment & $\begin{array}{l}\text { Males } \\
\text { caught }\end{array}$ & Paired & $\begin{array}{l}\text { Caught before } \\
\text { pair formation }\end{array}$ & $\begin{array}{l}\text { Established } \\
\text { paternity }\end{array}$ & $\begin{array}{l}\text { Laying } \\
\text { date }\end{array}$ & $\mathrm{SE}$ & $\begin{array}{l}\text { Pairing } \\
\text { speed }\end{array}$ & SE \\
\hline \multirow[t]{2}{*}{2002} & $\mathrm{C} 1$ & 17 & 14 & 11 & 11 & 17.27 & 0.74 & 3.36 & 0.39 \\
\hline & $\mathrm{E}$ & 18 & 11 & 11 & 10 & 20.64 & 1.48 & 6.18 & 1.31 \\
\hline \multirow[t]{3}{*}{2003} & $\mathrm{C} 0$ & 22 & 11 & 5 & 5 & 21.40 & 2.91 & 9.00 & 3.36 \\
\hline & $\mathrm{C} 1$ & 21 & 15 & 8 & 7 & 21.88 & 1.53 & 8.88 & 1.42 \\
\hline & $\mathrm{E}$ & 22 & 11 & 9 & 9 & 23.11 & 1.69 & 5.11 & 1.54 \\
\hline \multirow[t]{3}{*}{2004} & $\mathrm{C} 0$ & 26 & 15 & 4 & 4 & 19.75 & 3.45 & 3.75 & 0.75 \\
\hline & $\mathrm{C} 1$ & 25 & 13 & 9 & 9 & 19.33 & 1.19 & 3.77 & 1.20 \\
\hline & $\mathrm{E}$ & 26 & 15 & 10 & 9 & 18.50 & 0.70 & 4.50 & 1.13 \\
\hline \multirow[t]{3}{*}{ All years } & $\mathrm{C} 0$ & 48 & 26 & 9 & 9 & 20.67 & 2.10 & 6.67 & 2.02 \\
\hline & $\mathrm{C} 1$ & 63 & 42 & 28 & 27 & 19.25 & 0.72 & 5.07 & 0.72 \\
\hline & $\mathrm{E}$ & 66 & 37 & 30 & 28 & 20.67 & 0.82 & 5.30 & 0.75 \\
\hline Total & & 177 & 105 & 67 & 64 & 20.07 & 0.55 & 5.39 & 0.52 \\
\hline
\end{tabular}

Sample sizes differ between columns because not all individuals were found paired at the end of the season; some males were caught after pair formation and some paternity analyses failed (see respective columns for sample sizes). The mean and standard error of laying date and pairing speed (day found nest building-day caught) are given in the last columns 
Pairing success

Almost half $(48 \%, N=67)$ of all the males caught early in the season before pair formation $(N=139)$ were found attending a brood later in the season. The other males $(52 \%$, $N=72$ ) may have been unable to attract a mate or may have bred outside our study area. In line with the prediction based on the selective advantage of early breeding (Sheldon et al. 2003), we found a high pairing success for both $E$ and C1 early in the season, which decreased through the breeding season (Fig. 1; relative capture date, Wald $\chi^{2}=$ 11.44, coefficient $=-0.128(0.038), d f=1, p<0.001)$. Previous work suggested that later in the season male pied flycatchers might be preferred by female collared flycatchers, which would be revealed in our experiment by an interaction between treatment and relative capture date. This suggestion is weakly supported by our data, as the pairing success of the E group declines less steeply through the season and is higher than the $\mathrm{C} 1$ group at the end of the season (Fig. 1; Wald $\chi^{2}=2.772, d f=1, p=0.096$ ). Differences in the average share of paternity between years was near-significant (Wald $\chi^{2}=5.298, d f=2, p=0.071$ ), but the treatment effect (Wald $\chi^{2}=2.351, d f=1, p=0.125$ ) was not significant. In conclusion, the pairing success of an individual decreases through the breeding season, and a non-significant interaction between treatment and capture date suggests a less steep decline for the E group.

\section{Speed of pair formation}

It is immediately apparent from Table 1 that the pairing speed shows great variation both between years and treatment groups, but not in a consistent way. This is reflected by the results of the GLM, as none of the variables in the models had a significant effect (GLM, relative capture date $F_{1,54}=1.363, p=0.248$, treatment $F_{1,54}=0.011$, $p=0.916$, relative capture date $\times$ treatment $F_{1,54}=0.028, p=$ $0.868)$.

\section{Male share of paternity}

There was no significant difference between the different treatment groups in the proportion of broods with extra-pair nestlings (eight of the $27 \mathrm{C} 1$ broods and 12 of the $28 \mathrm{E}$ broods; Fisher's exact test, $p=0.603$ ). The male share of paternity of the $\mathrm{C} 1$ group is similar to that in previous studies (85\%, Sheldon and Ellegren 1999) and fluctuates rather little over the years. The differences found between the $\mathrm{Cl}$ and the $\mathrm{E}$ groups were small and showed no significant effect of experimental treatment or size of the male's forehead patch (after manipulation) on the male share of paternity (Fig. 2a and Table 2a). Year effects were marginally significant but are hard to interpret; laying date had a significant negative effect on male share of paternity. These results indicate that the experimental treatment did not change the level of extra-pair paternity. This differs significantly from the pattern found in nature, where broods with a male pied flycatchers mated with a female collared flycatcher had much higher rates of extra-pair paternity (logistic regression comparing E pairs with female collared flycatcher mixed-species pairs (data from Veen et al. 2001): Wald $\left.\chi^{2}=28.434, d f=1, p<0.001\right)$.

An important question to address is that of whether the plumage manipulation had an effect at all, i.e. whether the experimental males were perceived by the females as 'pied' flycatchers. In case of an unsuccessful manipulation, the paternity levels might be better predicted by the original plumage characteristics. Re-running the analysis with the non-manipulated forehead patch sizes did, however, not change the outcome qualitatively, as only the laying date had a significant effect and the original size of the forehead
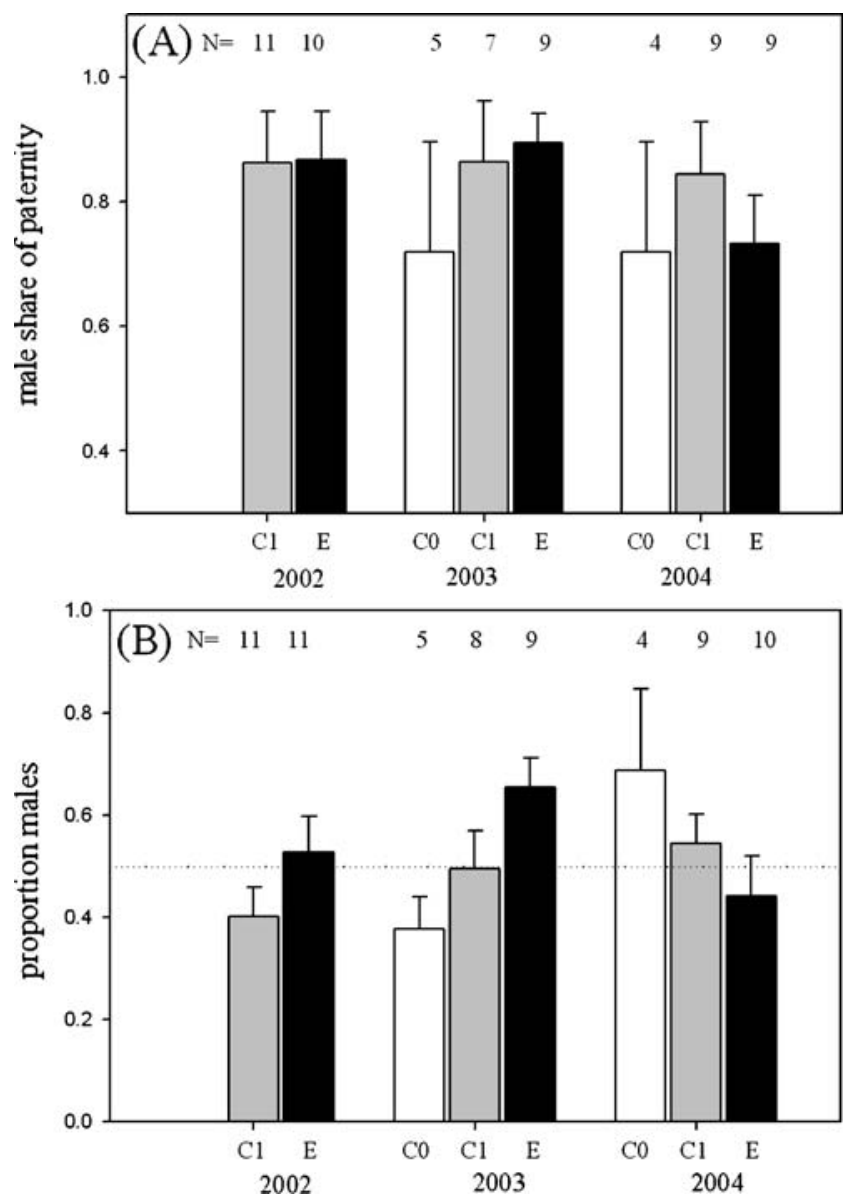

Fig. 2 Male share of paternity (a) and sex ratio (b) for the different experimental groups for the 3 years in which the experiment was conducted (mean with standard errors and sample sizes above bars). The three experimental groups are $C O$ (male only caught, no plumage manipulation treatment), $C 1$ (male painted with colourless blender marker pen to resemble collared flycatcher) and $E$ (male painted with black marker pen to resemble male pied flycatcher) 
Table 2 Logistic regression of the effects of treatment, year, laying date, and size of the male's forehead patch (after experimental manipulation) on male share of paternity (A) and sex ratio (B)

\begin{tabular}{|c|c|c|c|c|c|}
\hline Source & $d f$ & Wald $\chi^{2}$ & Coefficient & Standard error & $P$ value \\
\hline A treatment & 1 & 0.057 & & & 0.811 \\
\hline Year & 2 & 5.419 & & & 0.067 \\
\hline Laying date & 1 & 6.163 & -0.086 & 0.035 & 0.013 \\
\hline Forehead patch size & 1 & 0.684 & 0.005 & 0.006 & 0.408 \\
\hline B treatment & 1 & 1.906 & & & 0.167 \\
\hline Year & 2 & 2.380 & & & 0.304 \\
\hline Laying date & 1 & 0.147 & 0.010 & 0.026 & 0.701 \\
\hline Forehead patch size & 1 & 1.005 & -0.004 & 0.004 & 0.316 \\
\hline
\end{tabular}

patch size did not (logistic regression, Wald $\chi^{2}=0.307$, coefficient $=0.005, \mathrm{SE}=0.009, d f=1, p=0.579)$. Surprisingly, we did not find a significant relationship between the forehead patch size and the male share of paternity in the control group alone (logistic regression, Wald $\chi^{2}=1.097$, $d f=1, p=0.295$ ), which was expected based on previous studies. This complicates the validation of the effectiveness of the experimental treatment. A different way of trying to elucidate the effect of the experimental treatment is by dividing the males in three groups: pairs with a $\mathrm{C}$ male with a large forehead patch size $\left(>72 \mathrm{~mm}^{2}\right), \mathrm{C}$ male with a small $\left(<72 \mathrm{~mm}^{2}\right)$ or an $\mathrm{E}$ male. We expect to find a difference between these groups if females would perceive the $\mathrm{E}$ males as 'ordinary small patched males' and adjust their mating strategies accordingly (E and 'small C' would differ from 'large $\mathrm{C}$ ' but not from each other). There was no significant difference between the three groups detected (logistic regression (including laying date and the forehead patch categories), forehead patch; Wald $\chi^{2}=2.778, d f=2$, $p=0.249$ ). This might not come as a surprise, as the power to detect a difference is predicted to be low the lack of a significant relationship between patch size and male share of paternity (see above).

\section{Sex ratio}

The results of the sex ratio analysis again show much variation among groups and no consistent pattern between the different treatment groups (Fig. 2b). None of the factors contributed significantly to the final model, which contained as last factor the experimental treatment (Table 2b). The lack of effect differs from the patterns found in 'real' mixed-species pairs where the sex ratio was skewed towards sons. A direct comparison between the E group and male pied flycatchers engaged in a mixed-species pair (data from Veen et al. 2001) is not significant (logistic regression, Wald $\chi^{2}=0.88, d f=1$, $p=0.349$ ), but this is not surprising due to the small skew found in the latter pairs and the large variation in the $\mathrm{E}$ group.

\section{Comparison between $\mathrm{C} 0$ and $\mathrm{C} 1$}

In order to test whether the treatment per se might have affected individual behaviour, we compared the 'painted like a collared flycatcher' (C1) group with the controls that were only caught $(\mathrm{C} 0)$. From Table 1 , it is clear that a surprisingly large proportion of the $\mathrm{C} 0$ group was caught after pair formation and had to be excluded. As we assigned the newly caught males randomly to the treatment groups, the only plausible explanation we can think of is that this reduced pairing success of the $\mathrm{C} 0$ group is due to chance. As a consequence of the low sample sizes, we cannot draw firm conclusion from the $\mathrm{C} 0-\mathrm{C} 1$ comparison and will only discuss the results briefly. The pairing success decreased not only through the season for both the $\mathrm{C} 0$ and $\mathrm{C} 1$ groups but also differed significantly between the years. Speed of pair formation was not influenced significantly by any of the variables included in the model. The male share of paternity decreased significantly through the season for both groups and was furthermore significantly lower in the $\mathrm{C} 0$ group, for which we have no explanation. Sex ratios did not differ between the groups.

\section{Discussion}

The aim of this study was to experimentally mimic the situation where a female collared flycatcher pairs with a male pied flycatcher and to determine whether the high levels of extra-pair paternity and sex ratio skew towards males found in natural mixed-species pairs might be explained by an adaptive female mating strategy. We found very little evidence that this was the case, as broods with a 'pied-like' (E) male did not differ with respect to extra-pair paternity or sex ratio compared to control $(\mathrm{C} 1)$ pairs.

The interpretation of the results from studies in which no effect of the experimental treatment was found, like this study, are problematic because they can occur for several reasons, which we will discuss in turn. The lack of a 
treatment effect may be due to the female not having perceived the treatment or, alternatively, because although the treatment was perceived, the behaviour was not changed accordingly. From a scientific point of view, the latter situation is interesting, and neglecting such studies might have the unwanted side effect of causing a publication bias. Plumage manipulation alone will not change a male collard flycatcher into a 'perfect' pied male, as several other traits, most notably song (e.g. Qvarnstrom et al. 2006), are known to affect mating decisions, and these traits remained unmanipulated; this might of course affect the way females perceive manipulated males. We argue that in our study, it is unlikely that the females did not perceive the treatment at all as several earlier experimental treatments of species-specific characters, using similar methods, did change their behaviour. Saetre and colleagues have conducted studies in which the plumage of male flycatchers was manipulated (Saetre et al. 1993; Saetre et al. 1997). In the latter study, the plumage of male collared flycatchers was manipulated to make them resemble a male pied or semi-collared flycatcher (Ficedula semitorquata). Mate choice tests showed that female choice differed markedly depending on the species the manipulated male collared resembled, indicating a successful manipulation. Saetre and co-workers manipulated large parts of the plumage, but much less conspicuous manipulations of the size of the forehead patch of males have also been found to affect the behaviour of females (e.g. Qvarnstrom et al. 2000).

If we discard the explanation that females did not perceive the manipulation, as argued above, then our results suggest that mechanistic side effects as a consequence of species incompatibilities play an important role in creating the high levels of extra-pair paternity and sex ratio skew as found in natural mixed-species pairs. It is important to note that we cannot fully exclude a third explanation, namely a combination of both processes, but which effect is too small to detect with the sample sizes obtained. Females might change their mating strategies only slightly, for example increase the rate of extra-pair mating to such a level that all females engaged in a mixed-species pairing have at least one such mating. This does not need to entail a large increase of the frequency of extra-pair mating. A study by Michl et al. (2002) showed experimentally, by preventing the social male from transferring sperm during copulation, that seven out of nine females engaged in extra-pair mating. Not all extra-pair mating events with a conspecific result in an extra-pair fertilisation in pure-species broods. However, in mixed-species pairs, a single mating with a conspecific might result in a much higher fertilisation rate as a consequence of conspecific sperm precedence. The existence of such subtle changes in female mating strategy is weakly supported by the seasonal change of pairing success between the 'pied-like' (E) and the control (C1) groups.
The 'pied-like' group was more successful at the end of the season, which is in accordance with findings of an earlier study (Veen et al. 2001). An interesting finding of this study worth mentioning is that, in contrast to previous studies, we did not find a relationship between the size of the white forehead patch of the male and his share of paternity in the brood. This deserves further attention, as previous studies (e.g. Qvarnstrom et al. 2006) using collared flycatchers assumed this relationship and the lack of this relationship may have consequences for the conclusions drawn.

In this study, we find no convincing evidence that female collared flycatchers actively change their behaviour or sex allocation to counteract the negative fitness consequences of producing hybrid offspring. Our results suggest that mechanistic side effects play an important role, possibly together with (small) changes of female mating strategies. Small adaptations of the female mating strategy might be hard to detect but could have a pronounced effect on fitness calculation of apparently hybridising species and should therefore not be excluded.

Acknowledgements We would like to thank Lars Gustafsson for giving the possibility to work in the Uppsala University nest-box areas. Tristan Marshall generously provided extensive help with the paternity analysis. Thanks are also due to Mårten Hjernquist, Anna Qvarnström, Chris Wiley and Marco van der Velde for helpful discussions, practical help in the field and the molecular work (Katherine Thuman Hjernquist) and Oscar Vedder for testing the effect of experimental treatment on light reflectance. Financial support was obtained from The Netherlands Organization for Scientific Research (grant NWO-ALW 812.04.001) (TV). The plumage manipulation was approved by the Swedish National Board for Laboratory Animals.

Open Access This article is distributed under the terms of the Creative Commons Attribution Noncommercial License which permits any noncommercial use, distribution, and reproduction in any medium, provided the original author(s) and source are credited.

\section{References}

Badyaev AV, Hamstra TL, Oh KP, Seaman DAA (2006) Sex-biased maternal effects reduce ectoparasite-induced mortality in a passerine bird. Proc Natl Acad Sci U S A 103:14406-14411

Barton NH, Hewitt GM (1985) Analysis of hybrid zones. Ann Rev Ecolog Syst 16:113-148

Bennett ATD, Cuthill IC, Partridge JC, Maier EJ (1996) Ultraviolet vision and mate choice in zebra finches. Nature 380:433-435

Coyne JA, Orr HA (2004) Speciation. Sinauer, Sunderland

Ellegren H (1992) Polymerase-chain-reaction (Pcr) analysis of microsatellites - a new approach to studies of genetic-relationships in birds. Auk 109:886-895

Ellegren H, Gustafsson L, Sheldon BC (1996) Sex ratio adjustment in relation to paternal attractiveness in a wild bird population. Proc Natl Acad Sci U S A 93:11723-11728

Fricke C, Arnqvist G (2004) Conspecific sperm precedence in flour beetles. Anim Behav 67:729-732 
Gelter HP, Tegelstrom H, Gustafsson L (1992) Evidence from hatching success and DNA fingerprinting for the fertility of hybrid pied $\mathrm{x}$ collared flycatchers Ficedula hypoleuca x albicollis. Ibis 134:62-68

Grant PR, Grant BR (1992) Hybridization of bird species. Science 256:193-197

Grant PR, Grant BR (1997) Hybridization, sexual imprinting, and mate choice. Am Nat 149:1-28

Griffiths R, Double MC, Orr K, Dawson RJG (1998) A DNA test to sex most birds. Mol Ecol 7:1071-1075

Haldane JBS (1922) Sex ratio and unisexual sterility in hybrid animals. J Genet 12:101-109

Harper FM, Hart MW (2005) Gamete compatibility and sperm competition affect paternity and hybridization between sympatric Asterias sea stars. Biol Bull 209:113-126

Irwin DE, Price T (1999) Sexual imprinting, learning and speciation. Heredity 82:347-354

Kalinowski ST, Taper ML, Marshall TC (2007) Revising how the computer program CERVUS accommodates genotyping error increases success in paternity assignment. Mol. Ecol 16:1099-1106

Komdeur J, Daan S, Tinbergen J, Mateman C (1997) Extreme adaptive modification in sex ratio of the Seychelles warbler's eggs. Nature 385:522-525

McCarthy EM (2006) Handbook of avian hybrids of the world. Oxford University Press, New York

Michl G, Torok J, Griffith SC, Sheldon BC (2002) Experimental analysis of sperm competition mechanisms in a wild bird population. Proc Natl Acad Sci U S A 99:5466-5470

Moore AJ, Moore PJ (1999) Balancing sexual selection through opposing mate choice and male competition. Proc R Soc Lond B Biol Sci 266:711-716

Part T, Gustafsson L (1989) Breeding dispersal in the collared flycatcher (Ficedula albicollis) - possible causes and reproductive consequences. J Anim Ecol 58:305-320

Pfennig KS (2007) Facultative mate choice drives adaptive hybridization. Science 318:965-967
Price CSC (1997) Conspecific sperm precedence in Drosophila. Nature 388:663-666

Price T (2007) Speciation in birds, 1st edn. Roberts, Greenwood Village

Price TD, Bouvier MM (2002) The evolution of F-1 postzygotic incompatibilities in birds. Evolution 56:2083-2089

Primmer CR, Moller AP, Ellegren H (1996) A wide-range survey of cross-species microsatellite amplification in birds. Mol Ecol $5: 365-378$

Qvarnstrom A, Part T, Sheldon BC (2000) Adaptive plasticity in mate preference linked to differences in reproductive effort. Nature 405:344-347

Qvarnstrom A, Haavie J, Saether SA, Eriksson D, Part T (2006) Song similarity predicts hybridization in flycatchers. J Evol Biol 19:1202-1209

Saetre GP, Kral M, Bicik V (1993) Experimental evidence for interspecific female mimicry in sympatric Ficedula flycatchers. Evolution 47:939-945

Saetre GP, Moum T, Bures S, Kral M, Adamjan M, Moreno J (1997) A sexually selected character displacement in flycatchers reinforces premating isolation. Nature 387:589-592

Saetre GP, Borge T, Lindell J, Moum T, Primmer CR, Sheldon BC, Haavie J, Johnsen A, Ellegren H (2001) Speciation, introgressive hybridization and nonlinear rate of molecular evolution in flycatchers. Mol Ecol 10:737-749

Sheldon BC, Ellegren H (1999) Sexual selection resulting from extrapair paternity in collared flycatchers. Anim Behav 57:285-298

Sheldon BC, Kruuk LEB, Merila J (2003) Natural selection and inheritance of breeding time and clutch size in the collared flycatcher. Evolution 57:406-420

Svensson L (1992) Identification guide to european passerines, 4th edn. Märstatryck, Stockholm

Veen T, Borge T, Griffith SC, Saetre GP, Bures S, Gustafsson L, Sheldon BC (2001) Hybridization and adaptive mate choice in flycatchers. Nature 411:45-50 